\title{
Acute Intermittent Arteriomesenteric Occlusion of the Duodenum after use of Harrington's spinal Instrumentation: Case Report
}

\author{
A. Ohry MD, G. Zeilig MD, Y. Shemesh MD \\ Sir Ludwig Guttmann Spinal Cord Injury Unit, Rehabilitation Center, Sheba \\ Medical Center, Tel Hashomer, 52621 and Sackler School of Medicine, Tel Aviv \\ University, Israel.
}

\begin{abstract}
Summary
We report on a traumatic paraparetic patient, who developed acute intermittent arteriomesenteric occlusion of the duodenum after the use of Harrington's spinal instrumentation. This rare condition was treated conservatively. It is presumed that some degree of hyperlordosis of the lumbar spine by the rods was responsible for this phenomenon.
\end{abstract}

Key words: Spinal cord injury; Spinal shock; Intermittent arteriomesenteric occlusion; Paralyric ileus.

The diagnosis and management of abdominal emergencies in patients with spinal cord injury (SCI) is still a challenge in view of the neurological deficit and the physiological homeostatic changes. (Charney et al., 1975.) Soderstrom et al., 1983.) The problems of acute abdominal emergencies have been thoroughly discussed in the literature (Greenfield, 1949; Hoen et al., 1948; Ingberg et al., 1968; Juler et al., 1985, Miller et al., 1975; Tibbs et al., 1979). Following SCI three main stages of intestinal dysfunction may be seen:

1. Absence or depression of gastrointestinal (GIT) function during 'spinal shock'.

2. Automatic reflex activity.

3. Intestinal reconditioning (chronic phase).

During the 'spinal shock' phase, there is often paralysis of intestinal peristalsis, faecal retention, meteorism, paralytic ileus, acute gastric dilatation, or bleeding from 'stress ulcers'. During this phase patients are usually given corticosteroids and heparin. Epstein et al. (1981) found that the incidence and degree of GIT bleeding did not appear to be affected by the dose of corticosteroids or by the regimen of heparin administration.

Acute intermittent arteriomesenteric occlusion of the duodenum (Wilkie's syndrome), (AIAOD syndrome) may rarely occur in SCI patients due to the hyperextension of the lumbar spine caused by putting a pillow under the pati- 


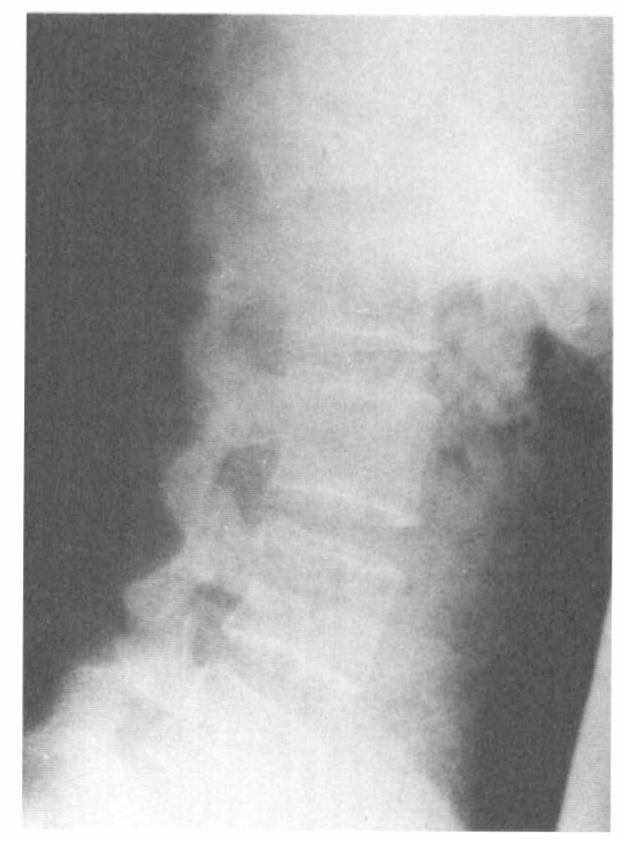

Figure 1 Fracture dislocation of the $\mathrm{L}_{1}$ vertebra.

ent's back to achieve postural reduction. The following case report describes a patient with SCI who developed the AIAOD syndrome after the insertion of Harrington's spinal instrumentation.

\section{Case report}

A 27-year-old man was admitted to our hospital after falling from a height of 5 metres (work accident). Neurologically, he had incomplete paraplegia below $\mathrm{L}_{2}$. Myelography and a CAT scan revealed a fracture and posterior dislocation of the $L_{1}$ vertebra (Fig. 1). After some neurological deterioration occurred, laminectomy of the $\mathrm{L}_{1-2}$ vertebrae and stabilisation with Harrington's rods were performed (Fig. 2). Four days later the patient was transferred to our rehabilitation ward. Three days later, that is a week after the operation, the patient had severe abdominal pains, nausea and vomiting. Examination showed abdominal swelling, decreased peristalisis, and tenderness. His temperature was $\mathrm{PO} 37.5^{\circ} \mathrm{C}$ and $\mathrm{PR}$ $38.6^{\circ} \mathrm{C}$. No neurological changes were detected. A plain abdominal X-ray showed a fluid level in the stomach, but no sign of free air (Fig. 3). A nasogastric tube was inserted and a large amount of fluid was aspirated. It is stressed that the patient was lying flat on his back. No corticosteroids were administered, only subcutaneous injections of heparin (5000 units twice daily). These clinical abnormalities reappeared three times. Nasogastric tube and drainage fluid were the only treatment: and each time peristalsis returned and the abdominal swelling subsided.

Upper GIT radiological investigation with contrast medium (barium) revealed free passage only to the second third of the duodenum (Fig. 4). After turning and tilting the patient the 'plug' was released. The AIAOD syndrome was the most probable diagnosis, caused by spinal hyperextension due to the Harrington rods. Since then, the patient has been seated and tilted (head up, and from side to side) after and during meals. The immobilisation period was shortened. An arteriogram was not performed. All routine laboratory values were within normal limits, apart from a transient leucocytosis. 


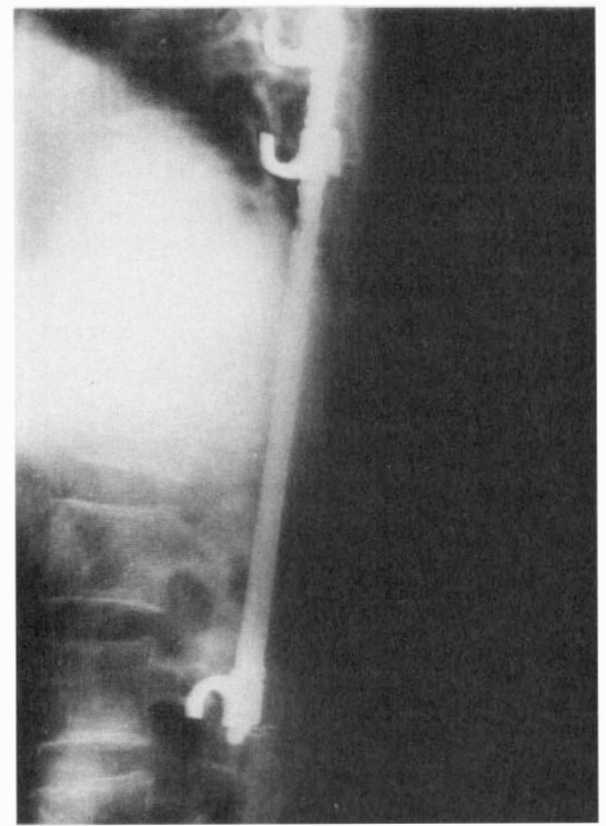

Figure 2 Spinal stabilisation with Harrington's rods.

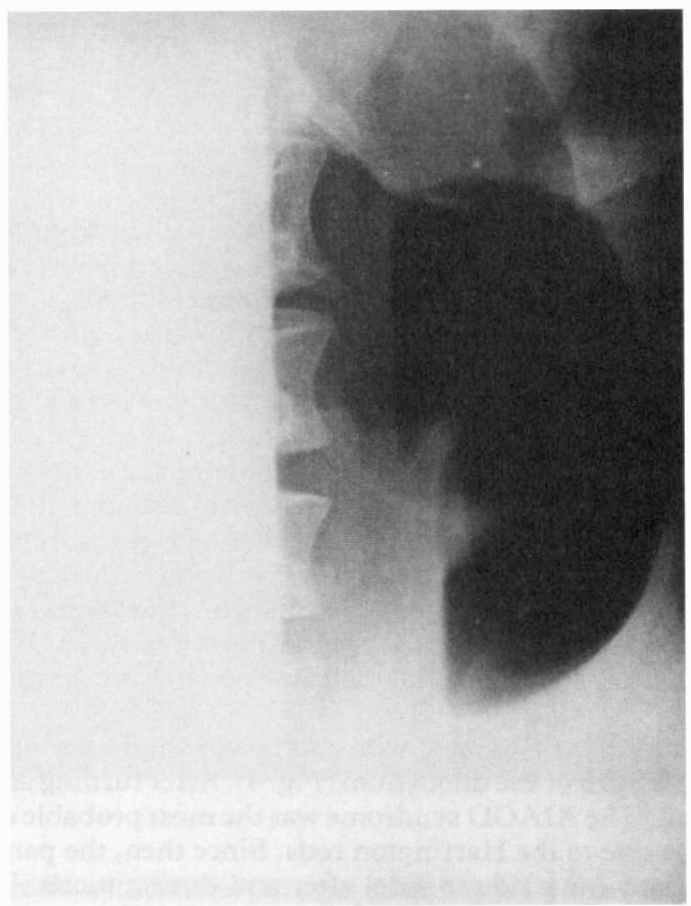

Figure 3 Plain abdominal film showing a fluid level. 


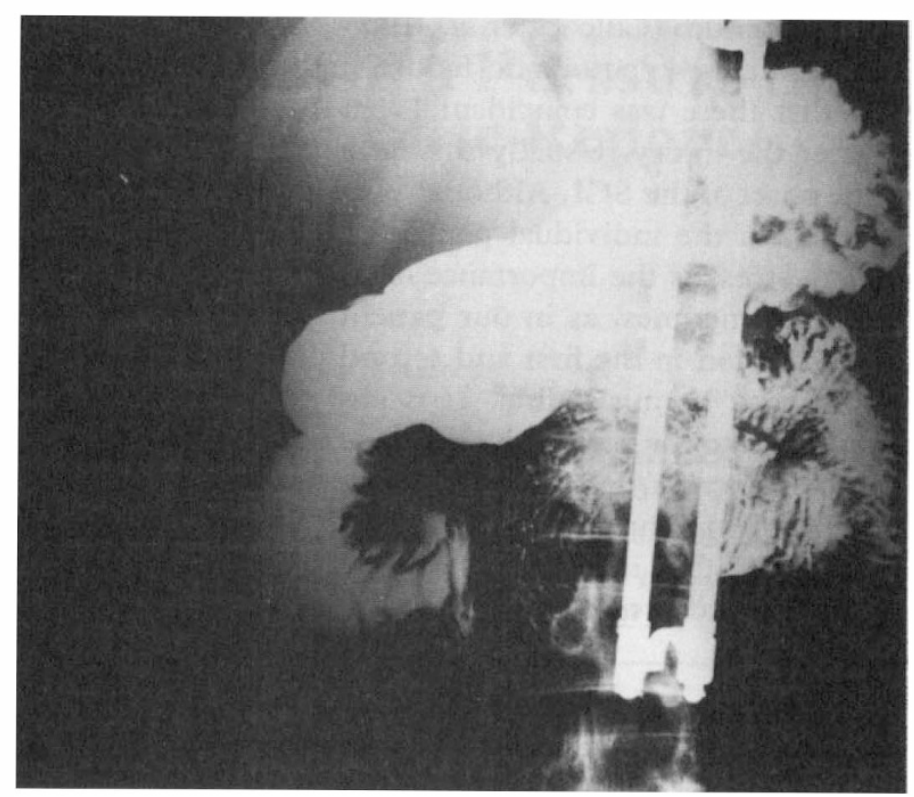

Figure 4 Radiological demonstration of free barium passage only to the second third of the duodenum.

\section{Discussion}

Obstruction of the duodenum after compression of the mesenteric root as a chronic intermittent condition is a well known, albeit rare, syndrome (Ruptov et al., 1964). There are many factors which contribute to the narrowing of the aorticsuperior mesenteric artery angle:

1. Rapid weight loss.

2. A flaccid abdominal wall which becomes spastic.

3. Prolonged supine positioning, especially with the head elevated.

4. Hyperlordotic deformity of the lumber spine.

Sensory impairment, emotional lability, muscle atrophy and accompanying complications such as paralytic ileus or 'stress ulcers' may cause a delay in the diagnosis of the AIAOD syndrome. Usually, correction of the lumbar hyperlordosis (e.g. removal of a pillow) relieves the situation immediately. To the best of our knowledge, this syndrome associated with Harrington's instrumentation has never been previously described. We have found however that iliofemoral thrombosis after correction of scoliosis with these rods was described recently (German et al., 1985).

In our patient, the rods were not removed, but early mobilisation was necessary. Further neurological recovery was noted, and the patient was later on subsequently able to walk unaided, and gained almost full control over his bladder and sphincters. Finally, the neurological status was an incomplete cauda equina syndrome (below $\mathrm{L}_{4}$ ). It seems that this patient may have had a duodenal obstruction due to this syndrome. Traditionally it has been thought to be due to a mechanical obstruction by pressure from the superior mesenteric vessels as 
they cross the duodenum (Colcock et al., 1968). Another theory is that neuromuscular derangement or 'automatic failure' may be responsible. We do not feel, however, that there was coincidental 'paralytic ileus' associated with the SCI a week after the injury. Usually this latter condition accompanies 'spinal shock' from the onset of the SCI. Although Wilkie's syndrome is widely known, it is accepted that in the individual patient precise diagnosis can be difficult. Another point to stress is the importance of the radiological verification of the obstruction; also, sometimes, as in our patient, the patient may have reduced the intestinal distension in the first and second part of the duodenum by prior emesis, and this may be misleading. It is also possible that a post-operative hematoma tracking into the area of the third part of the duodenum from the site superficial to the pancreas, lesser sac or posterior aspect of the stomach may cause a similar problem. The management of the 'acute silent atypical' abdomen (Block, 1983) among SCIP is still problematic, either from a direct blunt injury (Tibbs et al., 1979) or due to complications of treatment (Culig et al., 1984).

\section{References}

BLOCK MA 1983 Managing the silent atypical acute abdomen. Geriatrics 38:50-60.

Charney KT, Juler GL, Comarr AE 1975 General surgery problems in patients with spinal cord injuries. Archives of Surgery, 110:1083-1088.

Culig MH, Kelly EG, LAyton TR 1984 Toxic megacolon following spinal cord injury. Pennsylvania Medical fournal 87:51-52.

ColcOCK BP, BRAASCH JW Surgery of the small intestine in the adult. Major problems in clinical surgery, 1968 vol. 7, pp. 56-63, WB Saunders, Philadelphia.

EPSTEIN N, HeAd DC, RANSOHOFF J 1981 Gastrointestinal bleeding in patient with spinal cord trauma. Fournal of Neurosurgery 54:16-20.

GREENFIELD J 1949 Abdominal operations on patients with chronic paraplegia. Archives of Surgery 59:1077-1087.

GERMAN AW, SEIMON LP 1985 Iliof emoral thrombosis following Harrington's spinal instrumentation. Fournal of Bone and foint Surgery 67(Am):1273-1274.

HOEN TI, COOPER IS 1948 Acute abdominal emergencies in paraplegics. American fournal of Surgery 75:19-24.

INGBERG HO, PRUST FW 1968 The diagnosis of abdominal emergencies in patients with spinal cord lesions. Archives of Physical Medicine 49:343-345.

Juler GL, Eltorai IM 1985 The acute abdomen in spinal cord injury patients. Paraplegia 23: 118-123.

Miller LS, Staas WE Jr, Herbison GJ 1975 Abdominal problems in patients with spinal cord lesions. Archives of Physical Medicine and Rehabilitation 56:405-408.

Ruptov AS, LA BAN MM, Johnson EW 1964 Intermittent arteriomesenteric occlusion of the duodenum in a quadriplegic patient. Archives of Physical Medicine and Rehabilitation 45:418423.

Soderstrom CA, McArdle DQ, Ducker TB, Militello PR 1983 The diagnosis of intraabdominal injury in patients with cervical cord trauma. Fournal of Trauma 23:1061-1065.

TibBs PA, Bivius BA, Young AB 1979 The problem of acute abdominal disease during spinal shock. American Surgeon 45:366-368.

WILKIE, Sir David: in Surgery of the Small Intestine eds. ColCocK and BRAasch, in the series: 'Major Problems in Clinical Surgery' vol. 7. Saunders company. 